\title{
A fotografia como imagem-ficção em Alice in Wonderland, de Suzy Lee
}

\author{
Photography as fiction-image in Alice in Wonderland, by Suzy Lee
}

Mestre em Literatura e Crítica Literária (PUC/SP): doutorando em Literatura e Crítica Literária (PUC/SP), com bolsa FAPESP (Proc. 2018/10575-4); membro do Grupo de Pesquisa (CNPq) A voz escrita infantil juvenil: präticas discursivas. http.//orcid.org/0000-0001-8239-918X E-mail: luis.changmin@gmail.com

Recebido em: 15/2/2019. Aprovado em: 20/7/2019.

Publicado em: 16/12/2019

Endereço:

Tre 984 Sala 4 E03, $4^{\circ}$ andar. Perdizes, São Paulo, SP. CEP: 05014-901.
Luis Carlos Girão

Pontifícia Universidade Católica de São Paulo, Programa de Pós-Graduação em Literatura e Crítica Literária, São Paulo, SP, Brasil.

\section{RESUMO}

O presente escrito visa a refletir sobre a escolha da fotografia como elemento constitutivo e potencial da narrativa pictórica em Alice in Wonderland (2002), de Suzy Lee. Em seu primeiro livro-imagem, a book artist sul-coreana utiliza-se da linguagem visual fotográfica para estruturar e registrar jogos de revelação/falsificação em imagens que lampejam incessantes representificações ao clássico da Literatura Infantil escrito por Lewis Carroll. Para refletirmos sobre esse processo de ficcionalização imagético, tomaremos as reflexões de Philippe Dubois (2016, 2017) sobre o conceito de imagem-ficção, vertente essa exponencial no campo da arte-fotografia contemporânea. E, para nos auxiliar a pensar sobre o reposicionamento sensível do olhar proposto por Suzy Lee em seu livro híbrido - entre o literário, plástico, fotográfico -, buscamos em Georges Didi-Huberman (2010, 2013, 2015,2017 ) as compreensões de dupla distância e de montagem como limiares que irrompem diante do leitor, criança, jovem ou adulto, produzindo estranhamentos ao seu experienciar a aura da obra de arte.

Palavras-chave: Fotografia. Imagem-ficção. Montagem. Narrativa pictórica. Suzy Lee.

\section{ABSTRACT}

The present paper aims to reflect on the choice of photography as a constitutive and potential element of Suzy Lee's Alice in Wonderland (2002) pictorial narrative. In her first picture-book, the South Korean book artist uses photographic visual language to structure and record some revelation/ forgery games in images that flash incessantly representifications to Lewis Carroll's classic title of Children's Literature. Reflecting on this process of imaginary fictionalization, we take the recent writings of Philippe Dubois $(2016,2017)$ on the concept of fiction-image, an exponential aspect in the field of contemporary art photography. And to help us out thinking about the sensible repositioning of the look proposed by Suzy Lee's hybrid book - among the literary, plastic, photographic arts -, we've looked for Georges Didi-Huberman's writings (2010, 2013, 2015, 2017) on the double distance comprehension and the montage as thresholds that erupt before the reader, child, young adult, or adult, producing defamiliarization to his experience with the work of art's aura.

Keywords: Fiction-image. Montage. Photography. Pictorial narrative. Suzy Lee. 


\section{Introdução}

$\mathrm{O}$

clássico jogo antagônico do real vs. imaginário, realidade vs. fantasia, é um dos principais eixos na composição narrativa de um dos maiores clássicos da Literatura Infantil publicado na segunda metade do século XIX pelo autor britânico Lewis Carroll: Alice's Adventures in Wonderland (1865). Não muito diferente é o jogo de mise en scène que a autora sul-coreana Suzy Lee opta ao multiplicar as possibilidades de um embate do seu leitor com esse jogo.

Sem qualquer intuito de realizar uma análise comparativista entre as obras de Carroll e Lee ${ }^{2}$, nossa proposta traz mais uma leitura, uma olhada para os jogos de revelação/falsificação estruturais na narrativa pictórica de Alice in Wonderland (2002) - releitura em imagens plásticas, fotográficas, ao original de 1865 -, em sua especificidade pela escolha da fotografia como linguagem visual do mostrar esses jogos. Para efeito de contexto de nossa reflexão, trazemos o que o crítico e filósofo francês Georges Didi-Huberman (2010) afirma sobre o leitor de imagens, por seu turno, não ser apenas leitor, como também olhante - termo este que se refere ao ser de linguagem que vive o agora da dupla distância propiciada pela aura da obra de arte, isto é, a experiência do espaçamento tramado entre a obra e aquele que à olha e é, simultaneamente, por ela olhado.

Figurando na Artist's Book Collection do Tate Modern, em Londres, Alice é resultado de um mestrado em Book Arts pela Camberwell College of Arts, na Inglaterra, sendo o primeiro título literário publicado por Suzy Lee, artista plástica por formação. A book artist sul-coreana, conhecida internacionalmente por sua "Trilogia da Margem" - composta pelos títulos Espelho (2009), Onda (2008) e Sombra (2010) -, após dois anos de estudos na capital britânica, incluindo inúmeras visitas a exposições dedicadas ao legado de Lewis Carroll, tornou-se mestre nas artes do livro. Trabalhando a espacialidade sequencial do códex, ao estruturar uma narrativa constituída, intertextualmente ${ }^{3}$, pela mescla de fotografias e ilustrações recortadas, em preto e branco, reordenadas e coladas a objetos referentes aos bastidores de um teatro onírico, a artista oriental propõe

Este argumento introdutório justifica, em parte, a escolha por não trazer discussões acerca da intertextualidade para o campo de análise crítica ora proposto.

Uma análise comparativista mais aprofundada, acerca dos aspectos que envolvem esta tradução/adaptação de Lee para o livro de Carroll, pode ser encontrada em Cardoso e Girão (2016). uma experimentação com linguagens distintas (plástica, gráfica, fotográfica, teatral) em seu representar um dos maiores cânones da literatura universal.

Para efetuarmos uma leitura crítica da produção desse jogo de cena que compõe uma representação da Alice de Carroll em livro-imagem - livro composto por narrativa pictórica, ou seja, sem ou com pouquíssimas palavras (NIKOLAJEVA; SCOTT, 2011, p. 20-21) -, partimos da compreensão da curadora e escritora britânica Charlotte Cotton (2010, p. 49) quanto ao "uso da narrativa de uma história pela fotografia artística contemporânea" - também compreendida como "arte-fotografia", termo cunhado pelo historiador e teórico francês André Rouillé (2009) - como uma das vertentes exponenciais à produção artística na área dos estudos fotográficos na contemporaneidade.

Uma vez que falamos de um uso específico da fotografia enquanto produção de cenas fotografadas, eixo composicional nas páginas duplas do livro de Lee, estamos falando de uma compreensão contemporânea quanto aos usos e reusos das imagens. A ideia de imagem-ficção, que o pensador e teórico francês Philippe Dubois $(2016,2017)$ vem desenvolvendo em seus escritos mais recentes, em muito nos auxilia nesse refletir sobre um livro híbrido, que fica entre o literário, o plástico e o fotográfico, fonte potencial de estranhamentos ao leitor/olhante, seja ele criança, jovem ou adulto. Esse borrar as fronteiras nas artes, bem como na faixa etária de um público alvo previsto, causando rupturas nos modos de ver e ler, ação iniciada já na virada dos séculos XIX para XX, ao boom visual detonado pelo advento da fotografia como linguagem visual e, consequentemente, do cinema como reoperador das imagens em sua relação com o olhar humano, tão bem refletida pelo crítico e pensador germânico Walter Benjamin (2012), é uma das características mais essenciais à compreensão da arte contemporânea, hoje.

Por fim, ao entendermos a narrativa pictórica como uma sequência de cenas fotografadas produzida ficcionalmente, reforçando o jogo de revelação/falsificação entre realidade vs. fantasia, buscamos, também em Didi-Huberman (2013, 2015, 2017), a compreensão da "montagem" enquanto método de (des)composição de imagens, essencial no embate do olhante com o fazer artístico contemporâneo. 


\section{A fotografia mostrando os níveis de mise en scène}

Não muito comum na produção literária para o jovem leitor ${ }^{4}$, a fotografia, por muito tempo, foi compreendida enquanto linguagem visual indicial, ou seja, registro visual de algo existente anterior à sua superfície de mostragem. Como elemento estranho à construção visual desses livros já híbridos - os livros publicados enquanto literatura para crianças e jovens são exemplares do campo experimental próprio a esse fazer artístico contemporâneo, sem deixar de mencionar o fato de que são herdeiros do experimentalismo de autores como os surrealistas, na primeira metade do século XX -, a fotografia coloca em dúvida seu caráter indicial no livro de Lee.

Ao deixar de lado a ideia de um "isso foi" para colocar em primeiro plano um "isto é" sinestésico, no mostrar das páginas duplas em papel de gramatura mais densa e superfície fosca, estimulando sensações táteis e sonoras, quase como o manusear de um álbum de fotografias, a linguagem fotográfica no livro-imagem de Suzy Lee marca níveis de mise en scène que não cessam de re-significar o jogo realidade vs. fantasia. Essa marcação nos aproxima do conceito de imagem-ficção, sobre o qual Philippe Dubois vem se debruçado ao refletir sobre os usos da fotografia na contemporaneidade. Segundo Dubois (2017, p. 45), a imagem-ficção "existe no seu ato mesmo de mostrar-se". Tratase da representação de um mundo possível, ficcional,

não mais alguma coisa que esteve presente, mas algo que está aqui, diante de nós, ao alcance. Algo que podemos aceitar ou negar, e não mais um traço de alguma coisa que foi. Um mundo possível, sem critério de fixação, e que existe em sua demonstração mesma, presentificada e presente, sem ser necessariamente um traço de um mundo anterior. Uma imagem pensada como um universo de ficção, e não mais como um universo de referência (DUBOIS; BETHONICO, 2016, p. 65).

Partindo desse entendimento, poderíamos apontar, ao menos, três momentos desse mergulho de ficcionalização imagético, do cair de Alice pelo buraco

A Literatura, dita, infantil e juvenil contemporânea, de maneira geral, utiliza técnicas mistas, entre a ilustração e a colagem, como principais meios de composição dos seus textos em linguagem visual, não sendo a fotografia um elemento comum nessa produção. do Coelho Branco, na proposta de mise en scène mostrada por Suzy Lee: na performance (o teatro que se apresenta desde a capa do livro); na lareira (o revelar desse momento lúdico de um brincar com objetos e recortes do mundo, real e ficcional); e no livro (o objeto que se revela enquanto espacialidade sequencial da ficção de uma ficção).

Ao propor, da capa às primeiras duplas, um adentrar do olhante nesse livro-teatro, Lee reúne linguagens das artes plásticas, das artes cênicas e, essencialmente, da fotografia, em um mostrar de silhuetas pretas, em primeiro plano, acomodando-se para apreciar um espetáculo, em segundo plano, intitulado "Alice in Wonderland" - cenário à mostra já na capa do livro. Ao virar de páginas, no dar sequência a essas cenas, testemunhamos um ato que diferencia esse livro-imagem dos demais livros compostos exclusivamente por linguagem visual e impressos na chave do "infantil e juvenil": o ato de mostrar-se da narrativa se concentra nas páginas ímpares, à direita, das duplas. As páginas pares, à esquerda, trazem uma superfície escura, isolando silêncios e direcionando o drama do olhar para a performance que acontece do levantar as cortinas à exposição de uma personagem feminina em recorte de fotografia. Poderíamos dizer que se trata de um quase índice do real, não fosse o imediato processo de metamorfose, de fotografia para desenho, que essa personagem experiencia em resultado do seu encontro com um Coelho Branco - este, em princípio, um recorte de desenho.

Ao passo que a narrativa vai se desenrolando enquanto performance no palco em estilo vitoriano, evoluindo visualmente pelo uso de um zoom in, recurso próprio à linguagem cinematográfica, hibridizando ainda mais a superfície de mostragem, Lee age não apenas como fotógrafa de cenas pensadas e montadas por ela, como seu trabalho "lembra o do diretor de cinema que interliga criativamente fantasias e realidades coletivas" (COTTON, 2010, p. 51). Coletivas por reunirem elementos composicionais advindos das mais distintas estéticas: o palco da Alice de Lee, espaço da performance, reúne seus desenhos e fotografias recortados a cenários que misturam o tabuleiro do jogo de xadrez a reproduções das obras de nomes como Piero della Francesca e Diego de Velázquez (Figura 1), todos intercalados e potencializando esteticamente 0 jogo de revelação/falsificação no ato de perseguir o Coelho Branco. 
Figura 1 - Reprodução de dupla que intercala Las Meninas (1656), de Velázquez, às personagens

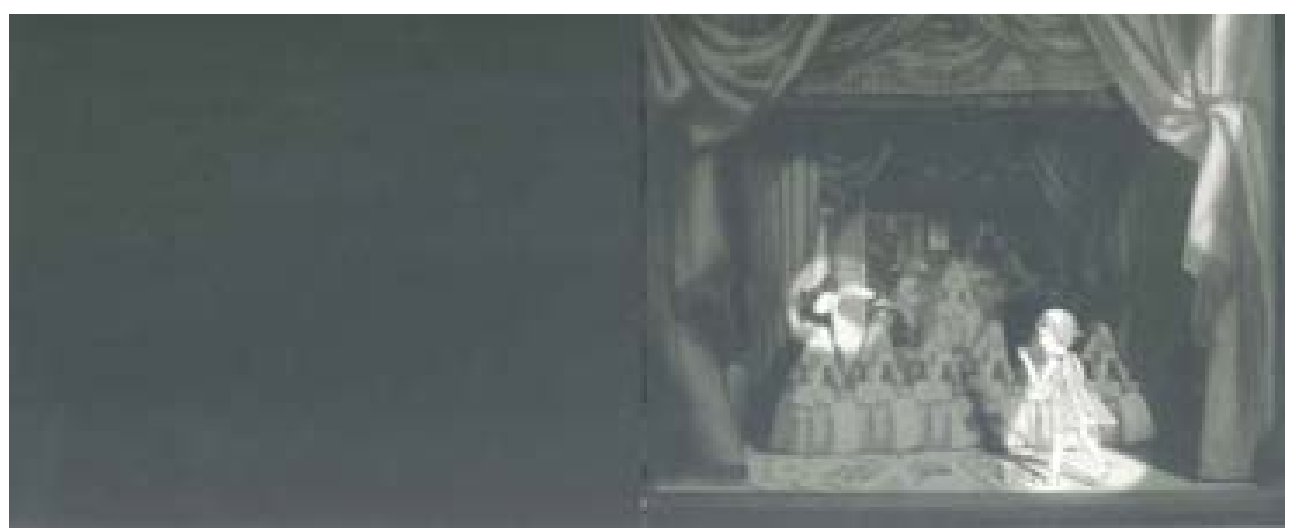

Fonte: LEE, 2002.

Cabe destacar a primazia na escolha de Suzy Lee pela utilização de fotografias em preto e branco, ressaltando a reprodução das obras de artes - tema este tão discutido e fundante nas mutações do olhar perceptivo à virada dos séculos XIX e XX (BENJAMIN, 2012) -, realocando esses trabalhos artísticos, classicamente localizados em museus, ao espaço da página dupla em um livro que não cessa de questionar o que é real e o que é fantasia nessas composições fotográficas. Esse reposicionar o olhante diante de um livro que é literário e plástico, que é fotográfico e, ainda assim, objeto de exploração das sensorialidades, leva-nos a um resignificar do cânone literário ainda no primeiro momento de ficcionalização imagético proposto na obra de Lee - afinal, estamos localizados nos bastidores da performance.

Em sua perseguição ao Coelho Branco, que, ao virar de uma página, invade o espaço da extremidade esquerda da dupla, anteriormente reservado ao silêncio do preto fosco, quebrando uma previsibilidade linear da sequência pictórica e desaparecendo com o palco do teatro, agora mostrando os bastidores desse fazer-se enquanto performance, Alice interage com uma série de objetos selecionados pela "diretora de cena" Lee para ressaltar o jogo real $v s$. imaginação. Dentre eles, citamos: a reprodução de uma rosa como espaço onde a garotinha em desenho recortado vive o esticar de seu corpo; o duplicar de ilustrações, da própria Lee e reproduções de Sir John Tenniel para os personagens Tweedledum e Tweedledee, espelhados pela utilização da margem central do livro, sua dobra; o drama marcado pela metamorfose do Coelho Branco, antes um desenho recortado e agora um híbrido excêntrico de corpo em tecido translúcido e cabeça em espuma com olhos vidrados (Figura 2); todos sob o "reino da mestiçagem", que André Rouillé (2009) destaca como ideia transformadora e que estabeleceu a fotografia como arte na contemporaneidade. Segundo Rouillé (2009, p. 340), somente dentro desse contexto, da mestiçagem de materialidades, que obras como as de Suzy Lee podem ser, "ao mesmo tempo, plenamente pictóricas e totalmente fotográficas". Hibridez de linguagem visual.

Figura 2 - Reprodução de dupla onde o "reino da mestiçagem" se dá no embate entre as personagens

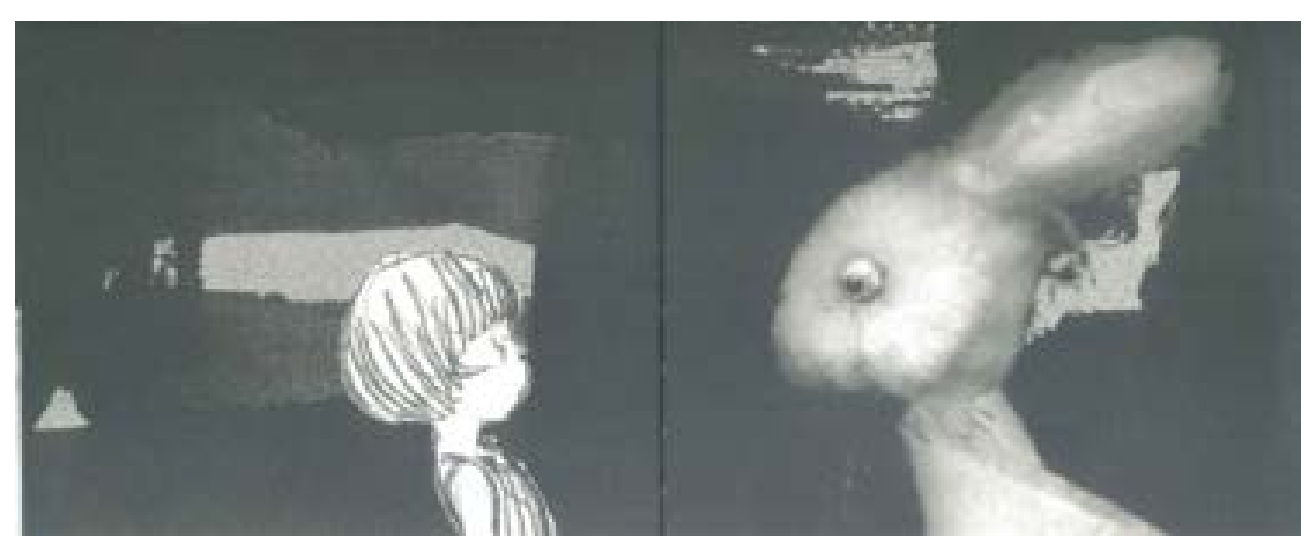

Fonte: LEE, 2002.

É no desvelar do segundo momento de ficcionalização imagético em Alice in Wonderland (2002), quando encerra-se a performance e o palco se revela, na "realidade", uma lareira em uma sala contemporânea, que testemunhamos uma outra característica das imagens-ficção: coloca-se em dúvida o caráter de "fixidade" da imagem fotográfica. Estamos nos referindo à "elasticidade temporal das imagens contemporâneas" (DUBOIS, 2017, p. 50, grifo do autor), ou seja, uma mutação nas ideias de tempo do olhar, da quarta dimensão das imagens, que se colocam em suspenso, permitindo que a superfície de mostragem seja, ao mesmo tempo, um antes no agora e um agora em 
metamorfose de devir futuro. Dubois (2017, p. 50) afirma que tudo isso acontece "de forma flexível, por variação contínua, sem cortes nem mudança de natureza". E é assim que Suzy Lee nos apresenta essa transição: do zoom in no palco da peça vivida por recortes de fotografias e ilustrações ao zoom out na sala onde está localizada a lareira-palco, que, na sequência, deixa de ser espaço de encenação pela interferência de uma figura feminina adulta que, anteriormente, seria silhueta compondo a plateia do espetáculo em códex.

A revelação desse fazer-se ficcional fotograficamente mimetiza o jogo cromático utilizado até aqui: as páginas à esquerda, até então, preenchidas em silencioso e dramático preto fosco, em resultado à metamorfose de Alice com o Coelho Branco em uma figura híbrida, una, levando ao fechar das cortinas, iluminam-se em um branco contrastante e criador de uma espacialidade "vazia". A própria Suzy Lee discute essa concepção de "páginas vazias" em seu ensaio teórico sobre os livros-imagem. Segundo a book artist sul-coreana:

Uma página vazia sem contexto pode ser um erro de impressão, mas se o branco [ou o preto] da página é essencial para adicionar sentido ao contexto, uma página sem palavras ou imagens não é uma página vazia (LEE, 2012, p. 112, grifo nosso).

Nesse sentido, pensar sobre a página branca, superfície de mostragem que marca um direcionar do olhar da página à esquerda à página da direita, onde ocorre a limpeza da lareira - ação mimetizada por uma réplica da figura feminina com cabeça de Coelho Branco no palco -, é pensar na utilização do espaço do códex como espacialidade de entrada para o imaginário do olhante agir sob as formas visuais à mostra nas fotografias, em seu papel de temporalizador da sequência pictórica. Falamos aqui de um descontínuo espaço-temporal que produz novas possibilidades para outros contínuos espaço-temporais. 0 que nos leva ao terceiro momento de ficcionalização imagético na obra de Lee: o revelar do objeto livro.

À progressão do zoom out, em um distanciar-nos cada vez mais da lareirapalco no espaço da página à direita, surge um elemento estranho à extremidade inferior da página à esquerda: a reprodução de um dedo polegar (Figura 3). Porém, esse dedo fictício aparece logo abaixo de onde o dedo do olhante estaria, até esse momento de sobressalto, segurando o códex em mãos. E os sobressaltos não cessam aí: na dupla seguinte, a previsibilidade do espaço de mostragem à direita é quebrada e ficamos diante da reprodução de um virar de páginas do livro que está sendo manuseado em seu ato mesmo de ser olhado. Mais uma vez, Suzy Lee nos faz questionar os aspectos de um "real" em seu livro-imagem. Não se trata apenas de um sonho-dentro-de-um-sonho ou de um espelho-dentro-de-um-espelho, como propunha Lewis Carroll com suas Alices, mas ao olhante contemporâneo é proposto um grau a mais desse mergulho na imagem fotográfica ficcionalizada: um livro-dentro-de-um-livro.

Figura 3 - Reprodução de dupla expondo o dedo ficcional que sobressalta a narrativa

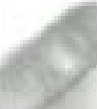

Fonte: LEE, 2002

Sendo uma book artist, Suzy Lee propõe formas distintas de se viver a experiência estética com o códex em seu abrir, folhear e ver/ler das páginas, não apenas como receptáculos de informações visuais, mesmo verbais - como é o caso do título na capa e da frase de Lewis Carroll nas últimas duplas: "A vida o que é, senão sonho?"5 -, mas como mensagem que ressignifica, concomitantemente, todas essas inscrições. Não à toa chegamos ao que se entende por última dupla e ficamos diante de uma página par, à esquerda, com uma fotografia emoldurada da sala onde estava a lareira-palco, em segundo plano, sendo aplaudida por um Coelho Branco que é um híbrido de silhueta preta e cabeça de espuma branca,

5 Do original: Is all our life, then but a dream? 
em primeiro plano, com seu olhar direcionado aos olhos do olhante: lampejo que atualiza todos os mergulhos ficcionais propostos até aqui.

A narrativa pictórica de Alice in Wonderland (2002) se faz em uma sequência de cenas que concentram toda uma composição visual fotográfica de captação de instantes, em um clique encenado capta-se toda uma história que traz seus próprios elementos de espaço e tempo. Essa característica aproxima as duplas individuais de Lee daquilo que Charlotte Cotton (2010, p. 49) entende por fotografia de quadros (tableau photography) ou de quadros-vivos (tableauvivant photography), próprios à arte-fotografia contemporânea.

Entendendo essa sequência de quadros-vivos, de duplas fotográficas, enquanto imagens-ficção que despertam sobressaltos, estranhamentos no olhar do olhante, faz-se necessário também refletir sobre o processo de (des) construção dessas cenas para (re)construí-las em novas possibilidades a partir daquilo que elas despertam no imaginário do olhante criança ou jovem.

\section{2 (Des)montagem fotográfica no olhar}

0 jogo de revelação/falsificação do mise en scène proposto no livro de Lee é dialética potencial e própria dos estímulos lançados ao olhar pelo fazer artístico experimental na contemporaneidade. No entanto, essas mutações do olhar perceptivo, no instante do "Ver" a superfície de mostragem e na duração do "Olhar" os elementos que compõem esse mostrar, são assuntos previamente discutidos por Walter Benjamin em seu clássico texto A obra de arte na época de sua reprodutibilidade técnica (2012), pelo advento da fotografia não apenas como arquivamento visual de fatos reais, mas como difusora da arte a espaços que não só as galerias e os museus. Esse aspecto da aura da obra de arte, ou seja, "de um poder do olhar atribuído ao próprio olhado pelo olhante", tão discutido por Georges Didi-Huberman (2010, p. 148, grifo do autor), à luz benjaminiana, é base para nos demorarmos um pouco mais acerca do processo de apreensão e afecção do olhante diante de um livro-imagem como o de Suzy Lee - composto em narrativa pictórica por imagens-ficção fotografadas.

0 olhante criança ou jovem, enquanto ser de linguagem que vive a dupla distância diante de uma obra de arte, ou seja, que experiencia a aura, é sujeito em processo de ressignificação do seu repertório em um embate direto ou indireto com as enunciações que apresentam e representam um "real". No caso de Alice in Wonderland (2002), enquanto sequência de imagens-ficção, referimonos a um real não realidade: fotografia, no entanto, ficcional. E, enquanto ficção, rastros de um real em ressignificação nos espaçamentos silenciosos entre o olhar que vê/lê e olha aquilo que o olha de volta, simultaneamente.

Esse regime do olhar, sempre duplicado, em um distanciar-se que é pura temporalidade e duração de um agora da experiência de cognição, encarna-se em um livro que traz novas mostragens e modos de mostrar as potencialidades de um clássico da Literatura Infantil que brinca ludicamente com o jogo antagônico do real vs. ilusão. E os três momentos de ficcionalização imagéticos sobre os quais nos demoramos anteriormente só condizem à potência implícita nas imagens se o olhante efetuar o regime duplicado do olhar. A execução desse regime da dupla distância não poderia ser mais bem exemplificada que pelas ações de desmontar e remontar as imagens, propostas por Didi-Huberman (2015, p. 131-139). Segundo o filósofo francês:

Uma imagem que me desmonta é uma imagem que me interrompe, me interpela, uma imagem que me deixa confuso, privando-me momentaneamente de meus recursos, faz-me perder o chão (DIDI-HUBERMAN, 2015, p. 131).

O ficar diante de cada uma das cenas que constituem a narrativa pictórica de Lee é sobressalto que confunde, que faz perder o chão. Nesse espaço-tempo do instante de uma imagem-ficção, do expor-se às "interrupções" (DIDI-HUBERMAN, 2017, p. 86, grifo do autor) provocadas por uma imagem resultante da captura fotográfica de uma cena montada como proposta de incitação fabular, narrativa, dentro de um encadear próprio à linearidade do objeto livro, o olhante se encontra diante de uma estranheza: ele vive, corporifica a "dialética do montador", isto é, "daquele que 'dis-põe' separando, depois reajuntando seus elementos no ponto de sua relação mais improvável” (DIDI-HUBERMAN, 2017, p. 87, grifo do autor). Seja por estímulos lançados pela encenação transgressora do cânone literário, performance esta que transpassa os bastidores onde realidade e ficção estão misturados ficcionalmente, ambientando uma dupla perseguição de protagonistas, em um livro-dentro-de-um-livro; ou pelo ir e vir no virar de páginas para buscar os índices de um "isto não estava aqui antes", 
índices mutáveis na duração de uma página dupla metafictícia aberta diante do olhar, a tarefa do olhante como montador dessa narrativa onírica é pontuada no instante liminar de um agora da leitura da fotografia que é montada, desmontada e remontada no olhar. É nessa interrupção desencadeada por um universo de ficção que as relações, de fato, mais improváveis surgem e não cessam de ser atualizadas a cada novo mostrar de estranhezas nas imagens-ficção.

A ação de ressignificar o encadeamento narrativo a cada virar de folha e varredura das formas visuais, inscritas ficcionalmente na superfície de mostragem do papel em gramatura mais densa, afeta os sentidos - não só do olhar, como também do tato e da audição. Esse fenômeno perceptivo de extrema potência significante acontece pelo fato de o olhante estar diante de uma obra pensada e executada na ambiguidade da língua da arte. Em particular, trata-se de um espaçotempo de leitura que ganha significações possíveis pela posição privilegiada e específica da página dupla no códex, por estar em um livro. No entanto, se cada página dupla é olhada, vivida como uma imagem-ficção individual, um mundo ficcional possível, ainda que dentro de uma sequência pictórica, não nos surpreende que uma das referências de Suzy Lee para cenário do teatro lúdico em sua Alice seja a montagem propiciada por René Magritte em Les Valeurs personnelles (1952) - um quarto onírico composto pela mistura de elementos do real (Figura 4).

Figura 4 - Reprodução de dupla onde os “valores pessoais" de Magritte desarmam a Alice de Lee

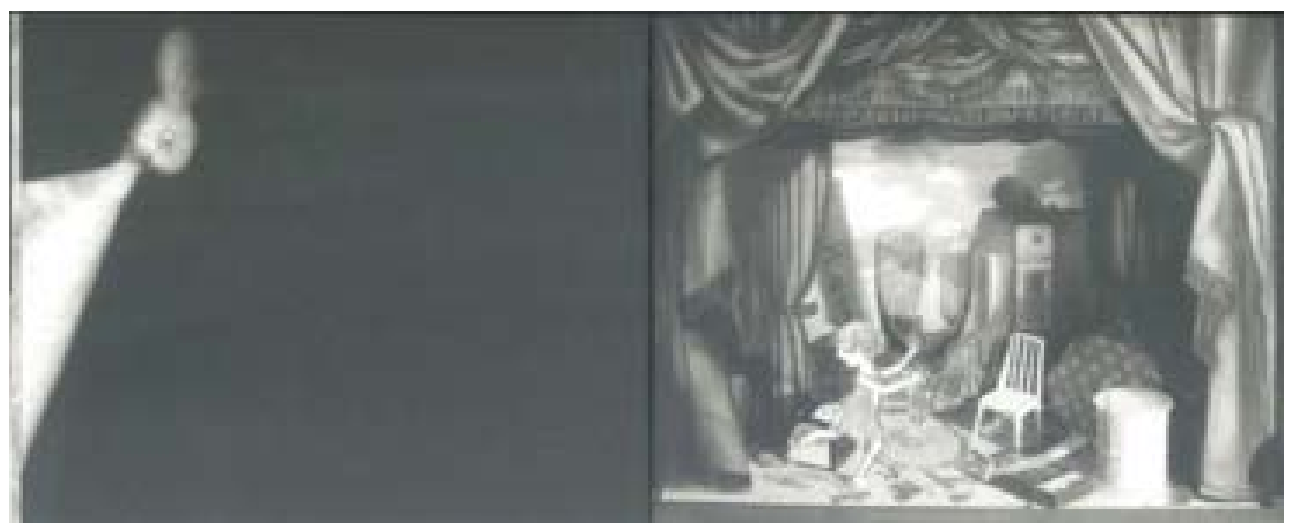

Fonte: LEE, 2002.
Os benefícios ficcionais de uma montagem fotográfica proposta ao olhante pelo livro-imagem Alice in Wonderland (2002) se assemelham à proposta de montagem fotográfica de André Malraux à ocasião do seu livro Le Musée imaginaire (1947). Nesse título, o escritor e teórico da arte francês repensa os espaços do imaginário e os modos de narrar a História da Arte por reproduções fotográficas de imagens produzidas pelos mais distintos fenômenos artísticos (quadros, esculturas, construções arquitetônicas etc.) - algo que se aproxima do exercício inacabado pelo historiador e teórico cultural alemão Aby Warbug à idealização do seu Bilderatlas Mnemosyne (1929). A primeira metade do século XX, por sinal, é o período profícuo em experimentação de novas formas narrativas sem o uso de palavras, como o foram o cinema mudo e as animações.

Acerca da montagem no museu imaginário de Malraux, que estimula o olhar às ações de desmontar e remontar imagens artísticas fotografadas, Didi-Huberman (2013, p. 33, tradução nossa) afirma:

[...] é em seu espaço de leitura e confronto - à esquerda, à direita - que toda a dramaturgia do "Museu Imaginário" pode ser organizada. Foi somente nessa condição espacial, técnica, que Malraux conseguiu vislumbrar o objetivo que ele próprio se propusera: compreender a arte universal na extensão de seu campo diferencial e na própria unidade desse campo. Graças ao seu dispositivo técnico - fotografias postas em página - o "Museu Imaginário" garantiu que as obras estivessem diretamente relacionadas ${ }^{6}$.

No caso da Alice de Lee, os confrontos se dão no ato mesmo de o olhar (des) montar as imagens-ficção, as cenas fotografadas que expõem níveis cada vez mais complexos de um fazer-se ficção no espaço de mostragem do objeto livro. Seja no ficar diante da página dupla (com as páginas à esquerda "silenciadas" ou agindo em seu mostrar-se), seja no embate propiciado pela sequência pictórica dessas duplas, o olhante criança ou jovem nas duas primeiras décadas do século XXI, à diferença de formatos, encarna semelhanças com o

6 Do original: [...] c'est dans son espace de lecture et de confrontation - gauche, droite - que peut s'organiser tout la dramaturgie du 'Musée imaginaire'. C'est à cette seule condition spatiale, technique, que Malraux pouvait envisager de parvenir au but qu'il s'était fixé: comprendre l'art universel dans l'extension de son champ différentiel et dans l'unité même de ce champ. Grâce à son dispositif technique - photographies mise en page - le 'Musée imaginaire' fait donc en sorte que les oeuvres dialoquent directement. 
espectador do cinema na década de 1920, sendo ambos dispositivos por meio dos quais se empreende "serenamente viagens de aventuras" (BENJAMIN, 2012, p. 97). Nesse espaço-tempo dilatado, o movimento de um instante captado, mostrado, encadeado, carrega força visual suficiente para interromper qualquer contínuo de leitura linear - ainda mais quando esse contínuo é interrompido pelo drama de uma cena como a de Alice, até há pouco tempo perseguidora, correndo do, agora perseguidor, Coelho Branco, na direção contrária à virada de folha, ao dar continuidade à linearidade das páginas no livro, que é pura revelação da falsificação representada pela constituição das imagem-ficção (Figura 5) que compõem essa narrativa pictórica fotografada.

Figura 5 - Reprodução de dupla expondo os bastidores da imagem-ficção que é palco de nova perseguição

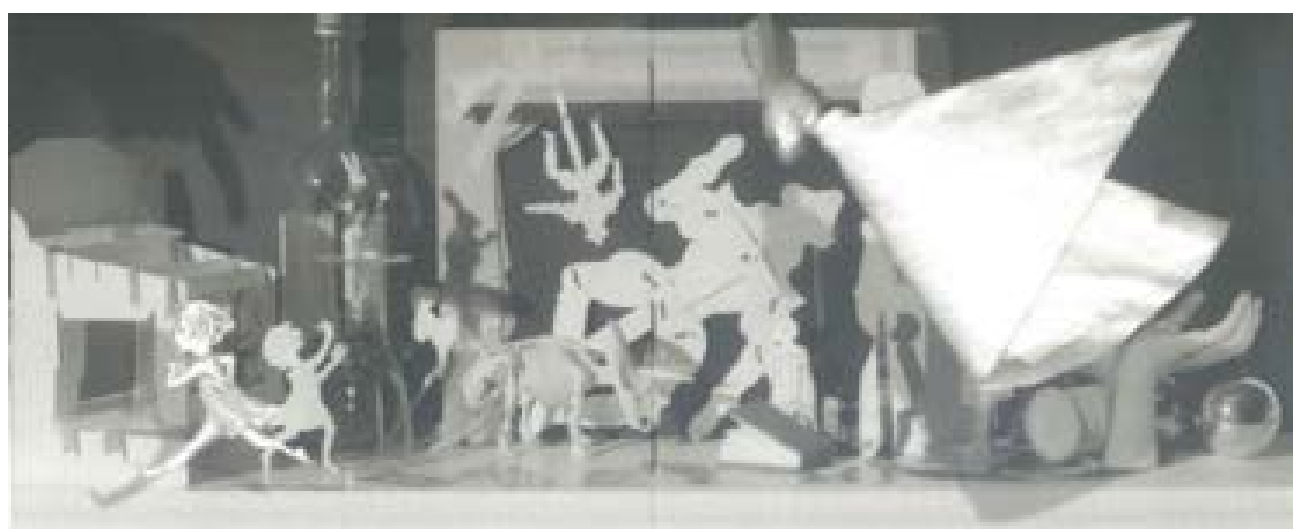

Fonte: LEE, 2002.

O (des)montar fotográfico no olhar que lê/vê a narrativa pictórica de Suzy Lee opera, de fato, um regime duplo no olhante pelo olhado (o livro), e vice-versa. Enquanto o ato de "desmontar" a imagem-ficção desfaz a "ilusão da continuidade" (DIDI-HUBERMAN, 2015, p. 132), operando descontínuos nas previsibilidades entre a performance, a lareira e o livro, como demonstrados anteriormente, o ato de remontar aproxima o olhar do olhante ao olhar do artista nessa "recomposição estrutural" (DIDI-HUBERMAN, 2015, p. 132). Em outras palavras, o olhante que fica diante das imagens-ficções que compõem a obra de Lee se aproxima do observador que se posiciona, em um museu, frente às obras mais ambíguas de Salvador Dalí; do leitor que segura, em mãos, um exemplar com ilustrações do clássico lúdico de Lewis Carroll; do telespectador que se deleita, no cinema, com as elaborações nonsense que marcam os filmes de Jan Švankmajer.

O remontar, enquanto resultado de um desmontar, um dispor a cena da imagem-ficção em uma dupla, mesmo no encadear de uma série de duplas fotografadas, estimula o imaginário do olhante na duração de seu olhar: ato puro de imaginar, de fabular. Segundo Didi-Huberman (2015, p. 135, grifo do autor): "A imaginação, a montadora por excelência, desmonta a continuidade das coisas somente para melhor fazer surgir 'afinidades eletivas' estruturais".

As afinidades propostas na estrutura visual do livro-imagem de Suzy Lee deslocam o olhar do olhante para outro campo de experimentação estética com o objeto livro, com a fotografia, com o movimento de ler e ver imagens. Nesse novo espaço híbrido, de potencial criativo, próprio ao remontar, o olhante criança, jovem ou adulto age sobre o artístico como o artista age sobre os elementos do real na produção de sua ficção, de sua arte, pois "a aura está vinculada ao seu aqui e agora" (BENJAMIN, 2012, p. 69), ao seu tornar-se presente no mostrar-se mesmo da imagem-ficção ${ }^{7}$.

\section{Considerações finais}

Cientes de que os aspectos levantados no presente escrito, pela limitação de seu formato, poderiam ser mais bem aprofundados, trazendo ainda mais leituras possíveis a partir das imagens potenciais criadas por Suzy Lee, concluímos nossa breve reflexão apontando como qualitativa a aproximação entre a literatura e a fotografia. No caso específico de Alice in Wonderland (2002), como livro híbrido que reúne recursos das mais distintas linguagens artísticas, verticalizar uma

Ao aproximarmos o leitor/olhante da figura do artista, fazedor de imagens artísticas, colocamos esse sujeito diante do livro-imagem de Lee como alguém diante de uma imagem única, logo, carregada de uma aura sua - questões de equivalências de sujeitos discutidas, em outras leituras, por Giorgio Agamben ( $O$ fogo e o relato, 2017) e Jeanne Marie Gagnebin (Limiar, aura e rememoração, 2014), à luz de Benjamin. Logo, não vemos motivo, nesse presente momento, para discutirmos questões acerca da desauratização das referências artísticas citadas nas imagens do livro. 
discussão sobre os níveis não trazidos à nossa pauta, mesmo prolongarmo-nos nos já expostos, muito teria a contribuir criticamente sobre a produção literária para crianças e jovens na contemporaneidade - ainda mais quando a linguagem visual fotográfica não se mostra como uma constante nessa produção.

Re-pensar a fotografia enquanto imagem-ficção no espaço de composição de uma narrativa pictórica, que representifica um cânone da Literatura Infantil, é propor ao olhante criança ou jovem uma potencialidade de fabular incessante no jogo da realidade vs. fantasia; é compreender que, se "a imagem se apresenta como um universo de ficção, e não mais de referência, ela está, no mínimo, mais aberta a possibilidades" (DUBOIS; BETHONICO, 2016, p. 66) de novas leituras. Trata-se de uma proposta artística em códex que convida o olhante a desmontar, remontando, no olhar, os elementos que ficcionalizam aquilo que já não é mais compreendido por traços de um real, mas elementos dialéticos de uma ficção montada.

Tal como o artista, o olhante é, ele próprio, montador dessas propostas que borram fronteiras nas artes contemporâneas, tão germinais na criação de narrativas que não se limitam a contar histórias pelo uso exclusivo do verbal, mesmo do visual, como também desdobram possibilidades ao repensarem a estrutura sintática do objeto livro e suas espacialidades temporais. E diante de imagens que revelam seu forjar, sua encenação, no agora de um mostrar, a esse olhante é lançado um desafio crítico-estético de buscar os mundos possíveis, as evoluções narrativas potenciais que se constituem em concomitância às leituras de si, às expressões de si.

\section{Referências}

BENJAMIN, Walter. A obra de arte na época de sua reprodutibilidade técnica. Trad. Francisco D. A. P. Machado. Porto Alegre: Zouk, 2012.

CARDOSO, Elizabeth P.; GIRÃO, Luis C. Alice in Wonderland: uma tradução literária em imagens por Suzy Lee. Signo, Santa Cruz do Sul, v. 41, n. 72, p. 65-75, set./dez. 2016. https:// doi.org/10.17058/signo.v41i72.7160

COTTON, Charlotte. Era uma vez. In: COTTON, Charlotte. A fotografia como arte contemporânea. Trad. Maria S. M. Netto. São Paulo: Editora WMF Martins Fontes, 2010. p. 49-79.
DIDI-HUBERMAN, Georges. Diante do tempo: história da arte e anacronismo das imagens. Trad. Vera Casa Nova e Márcia Arbex. Belo Horizonte: Editora UFMG, 2015.

DIDI-HUBERMAN, Georges. L'Album de l'art à l'époque du "Musée imaginaire". Paris: Éditions Hazan; Musée du Louvre, 2013.

DIDI-HUBERMAN, Georges. O que vemos, o que nos olha. Trad. Paulo Neves. 2. ed. São Paulo: Editora 34, 2010. https://doi.org/10.1590/1982-25542015120104

DIDI-HUBERMAN, Georges. Quando as imagens tomam posição. Trad. Cleonice P. B. Mourão. Belo Horizonte: Editora UFMG, 2017.

DUBOIS, Philippe. Da imagem-traço à imagem-ficção: o movimento das teorias da fotografia de 1980 aos nossos dias. Trad. Henrique Codato e Leonardo G. Pereira. Discursos Fotográficos: Londrina, v. 13, n. 22, p. 31-51, jan./jul. 2017. https://doi.org/10.5433/1984-7939.2017v13n22p31

DUBOIS, Philippe; BETHONICO, Marina R. A noção de fingere na produção visual contemporânea: estratégias para mundos possíveis através da imagem. ARS: São Paulo, v. 14, n. 27, p. 55-72, 2016. https://doi.org/10.11606/issn.2178-0447.ars.2016.117620

LEE, Suzy. Alice in Wonderland. Mantua: Corraini Edizione, 2002.

LEE, Suzy. A trilogia da margem: o livro-imagem segundo Suzy Lee. Trad. Cid Knipel. São Paulo: Cosac Naify, 2012.

NIKOLAJEVA, Maria; SCOTT, Carole. Livro ilustrado: palavras e imagens. Trad. Cid Knipel. São Paulo: Cosac Naify, 2011

ROUILLÉ, André. Terceira Parte: A arte-fotografia. In: A fotografia: entre documento e arte contemporânea. Trad. Constancia Egrejas. São Paulo: Editora SENAC São Paulo, 2009. p. 334344. https://doi.org/10.11606/issn.2316-9133.v25i25p462-468 